Juin 1999

$\mathrm{n}^{\circ} 9910$

\title{
A STRUCTURAL MODEL FOR US AGGREGATE JOB FLOWS
}

\author{
Fabrice Collard ${ }^{(1)}$, Patrick Fève ${ }^{(2)}$ \\ François Langot ${ }^{(3)}$ and Corinne Perraudin ${ }^{(4)}$
}

\section{(1) CNRS-CEPREMAP \\ (2) Université de Nantes LEN-C3E and CEPREMAP \\ (3) Université du Maine GAINS and CEPREMAP \\ (4) Université de Paris I EUREQua}

We would like to thank A. d'Autume, J.P. Benassy, R. Boucekkine, P. Cahuc, R. Cooper, S. Gregoir, P.Y. Hénin, T. Kollintzas, F. Kramarz, E. Lehmann, O. Licandro, R. Marimon and F. Portier. The data were kindly provided by J. Haltiwanger. Previous versions of this paper have also benefited from discussions during presentations at GMM (Cepremap), MAD (U. Paris 1), CREST (INSEE), IOBE (Athens), SEL (Louvain-laNeuve) and IDEI (Toulouse) seminars, and T2M 98 (Marseille), SED 98 (Philadelphia), EEA 98 (Berlin), Macrodynamic Workshop 98 (Vigo, Spain), SCE 99 (Boston) conferences. The traditional disclaimers apply.

Internet : Consulter le WEB : http://www.cepremap.cnrs.fr 


\title{
UN MODÈLE STRUCTUREL DES FLUX AGRÉGÉS DE MAIN D'EUVRE
}

Fabrice Collard, Patrick Fève, François Langot and Corinne Perraudin

\section{Résumé}

Les études récentes ont souligné l'existence d'asymétries dans la dynamique de l'emplois. Ce papier contribue à l'analyse de cette dynamique à travers une modélisation explicite de ses deux composantes : les créations et les destructions d'emploi. Nous proposons un modèle d'appariement intégrant des séparations endogènes et une hétérogénéité entre les entreprises. Les paramètres du modèle sont estimés à l'aide d'une méthode d'estimation par simulation. Nous testons alors l'aptitude des externalités d'échange, engendrées par le processus d'appariement, à (i) propager les chocs sectoriels sur le marché du travail et (ii) engendrer les asymétries observées dans les flux d'emplois agrégés. Les résultats indiquent clairement que le modèle est capable de capturer les asymétries des flux d'emplois américains.

\section{A STRUCTURAL MODEL FOR US AGGREGATE JOB FLOWS}

\section{Fabrice Collard, Patrick Fève, François Langot and Corinne Perraudin}

\begin{abstract}
Recent studies have highlighted the existence of asymmetries in employment dynamics. This paper contributes to the analysis of this dynamics through the explicit modelling of its two components - job creations and job destructions. We propose a simple matching model extended for endogenous separation and tractable heterogeneity. The parameters of the model are estimated using a simulation-based estimation method. We then test the ability of trade externalities, generated by the matching process, to (i) propagate sectoral shocks in the whole labor market and (ii) generate the observed asymmetries in aggregate job flows. The results clearly indicate that the model is able to match the observed asymmetries in US aggregate job flows.
\end{abstract}

Keywords: matching process, stochastic heterogeneity, asymmetries, nonlinear dynamics, simulation based estimation.

Mots clés: appariement, hétérogénéité, dynamique non-linéaire, estimation par simulation.

JEL Classification: C51, E24, E32 


\section{Introduction}

In most industrial countries, aggregate dynamics in labor market is essentially characterized by the following stylized facts: (i) vacancies and unemployment are negatively correlated (the so-called Beveridge curve), (ii) aggregate job flows are large within the business cycle, (iii) the destruction rate is more volatile than the creation rate, (iv) destruction and creation rates are negatively correlated. These stylized facts are now well established in the literature (See, e.g., Davis, Haltiwanger and Schuh [1996]). Further, two additional stylized facts have also emerged from time series analysis: $(v)$ employment adjustments display significant non-linearities (See, e.g., Burgess [1992]) and (vi) the distribution of job flows (more particularly destructions) also exhibits significant asymmetries. This later is also pointed out by Davis et al. [1996] who argue that "job destruction rises dramatically during recessions, whereas job creation initially declines by a relatively modest amount." (p.31). The ability of structural models to match the first four stylized facts has already been evaluated in the literature (See, e.g., Mortensen and Pissarides [1994]). Concerning stylized fact ( $v$ ), Burgess [1992] has shown that the matching model can account for non-linearities in aggregate employment dynamics. Nevertheless, in matching models, aggregate employment dynamics is generated by the dynamics of job flows - overall job creations and overall job destructions. An important issue of this type of model is thus to match the sixth stylized fact, as a large part of employment asymmetries may be accounted for by asymmetries in aggregate job flows. Hence, the purpose of this paper is to propose a model that can account for the whole set of stylized facts on aggregate job flows.

We propose a simple matching model extended for endogenous separation and (tractable) firm heterogeneity in the lines of Mortensen and Pissarides [1994]. Though relying on the later framework, our model essentially departs from it with three respects. We first relax the key assumption of job irreversibility. Thus, firing costs are not infinite, but are assumed to be flexible within the business cycle. Second, we relax the extreme assumption that newly-created jobs are the most profitable in the market. This amounts to assume that the matching process is totally random, in the sense 
that a firm does not observe the productivity of the worker it hires. Third, we do not rely on plant specific idiosyncratic shocks. This raises the question of the level of disaggregation assumed in the model. Davis and Haltiwanger [1992] have shown that plant specific idiosyncratic shocks are important to account for highly disaggregated phenomena on reallocation process. ${ }^{1}$ They however show that, as far as time variation in overall job destruction and overall job creation are concerned, the variance of idiosyncratic component of job flows amounts to only a small part of the overall variance of job flows (12-16 percents for overall job creation and 6-8 percents for overall job destruction). This suggests that a sufficient level of disaggregation for our purpose is the sectoral level. Thus, in this paper, we will consider an economy constituted by many sectors, each of them experiencing specific technology shocks. Given this sectoral stochastic heterogeneity and that firing costs are assumed to be internal to the firm, we test the ability of trade externalities, generated by the matching process, to propagate the sectoral shocks in the whole labor market and generate the observed asymmetries in aggregate job flows.

Given the structure of the model and given that stochastic processes do not have any observable counterpart, the structural parameters of the model are estimated using a simulation-based estimation method. ${ }^{2}$ This procedure can be easily implemented even when the likelihood function is intractable or when moments cannot be computed using direct integration methods. We use moments and descriptive statistics that encompass as many features of the data as possible in order to avoid too much arbitrariness. Thus, the set of moments combines usual moments (sample mean, variance and correlation) and higher order moments to match asymmetries in the data. We further develop a diagnostic test, in the lines of Gallant, Hsieh and Tauchen [1994], to locate potential failures of the structural model in terms of moment matching.

\footnotetext{
${ }^{1}$ Davis and Haltiwanger [1992] report the following stylized facts: (1) fluctuations of job reallocations across industries and regions are countercyclical, (2) the countercyclical behavior of job reallocation reflects time variation in the magnitude of idiosyncratic plant-level employment movements, (3) job reallocation rates among young, small and single-unit plants exhibit little or no systematic relationship in the cycle and (4) job reallocation among older, larger and multi-unit plants exhibits pronounced countercyclical patterns of variation.

${ }^{2}$ See e.g. Gallant and Tauchen [1996], Gouriéroux, Monfort and Renault [1993] and Smith [1993], and Gouriéroux and Monfort [1994] for a general statement of these methods.
} 
Our results indicate that the model matches the selected moments computed using quarterly data on creation and destruction rates in the US manufacturing sector and thus accounts for the aforementioned stylized facts. This first confirms our specification choices, and more particularly the degree of stochastic heterogeneity. Further, it is shown that the non-linearity generated by the theoretical model is sufficient to characterize the empirical distribution of the data. Hence, these results show that trade externalities provide a mechanism sufficient to match the distribution of aggregate job flows. More precisely, congestion effects limit the magnitude of the response of aggregate hirings following a positive technology shock. Conversely, aggregate congestion effects do not affect firing decisions, explaining the sharper response of firings following a negative shock.

The paper proceeds as follows. Section 1 presents the model. Section 2 is devoted to the econometric methodology. Finally, the estimation and testing results are reported in section 3 . This section also provides some insights on the propagation mechanisms. A last section concludes.

\section{A Matching Model of the Labor Market}

This section is devoted to the exposition of the behavior of individuals on the job market and to the characterization of the allocative process governing trade on this market.

\subsection{Technology and labor market arrangements}

\section{Technology}

We consider an economy that consists of many sectors, indexed by $j$. Each sector is composed of a large number of firms, indexed by $i$. Each firm has access to the constant returns-to-scale production function given by:

$$
Y_{i, j, t}=\left(\bar{a}(1+\kappa)+\eta_{j, t}\right) N_{i, j, t}
$$


$\bar{a} \geq 0$ is a scaling parameter, $\kappa \geq 0$ is a parameter that we introduce for convenience as it will become clear later on. ${ }^{3} N_{i, j, t}$ denotes the employment level involved in the productive process. Each sector is characterized by a specific implementation of technology, summarized by $\eta_{j, t}$ which is assumed to follow a covariance stationary AR(1) process:

$$
\eta_{j, t}=\rho \eta_{j, t-1}+\sigma \nu_{j, t}
$$

where $\nu_{j, t}$ is a zero mean, unit variance Gaussian white noise.

\section{Labor market arrangements}

We assume that allocation of resources in the labor market is driven by a search process for a given real wage. Each firm controls its hiring policy through $V_{i, j, t}$, the number of vacancies, and its firing policy through $F_{i, j, t}$, which denotes the level of firing. An important feature of this economy is that vacancies can be opened or closed but they cannot move between sectors.

Following Pissarides [1990], trade in the labor market is a costly and uncoordinated economic activity. There is a unified labor market where workers are perfectly mobile. In each and every period, a firm can post $V_{i, j, t}$ vacancies. As Bertola and Caballero [1994], we depart from the standard vacancy cost setup by letting the marginal cost of posting vacancies be an increasing function of the number of vacancies posted. The vacancy cost, $\psi\left(V_{i, j, t}\right): \mathbb{R}_{+} \longrightarrow \mathbb{R}_{+}$, is thus an increasing and convex function, and satisfies the additional assumption $\psi(0)=0$. The convexity assumption is necessary to determine vacancies for an individual firm within an heterogenous framework. Indeed, this convexity assumption prevents firms with high productivity from posting an infinite number of vacancies.

Each firm acts with a specific technology (the common -knowledge of the firm's sector) and cannot transfer its vacancies from a sector to another. Then, in each sector $j$, there exists a constant returns to scale matching function linking the number of hirings $H_{j, t}$ to the number of vacancies $V_{j, t}$ and unemployed workers $U_{t}$ in the aggregate

\footnotetext{
${ }^{3}$ It will turn out that $\kappa$ is linked to the wage setting rule.
} 
economy:

$$
H_{j, t}=h\left(U_{t}, V_{j, t}\right)
$$

$h($.$) is an increasing and concave function with respect to both arguments. It$ further satisfies: $h(0,)=.h(., 0)=0$. In each and every period, vacant jobs and unemployed workers are matched and move from trade to productive activity. In equilibrium, unemployment displays persistence because in each period some existing jobs disappear, resulting in a flow of new unemployed. The size of the population is normalized to one, therefore $U_{t}=1-N_{t}$ denotes the unemployment rate. Job vacancies and unemployed workers matched at time $t$ are randomly selected from the sets $V_{j, t}$ and $U_{t}$. The rate at which job vacancies are filled is given by $q_{j, t}=H_{j, t} / V_{j, t}$. This transition rate depends on the relative number of traders. Thus, there are two types of trade externalities. First, as $V_{j, t}$ increases, the probability of rationing firms increases. This trade externality amounts to a congestion externality. Second, as $U_{t}$ increases, the probability of rationing firms decreases: there thus exists some positive trade externality between traders. ${ }^{4}$

In each firm and in every period $t$, the number of employment outflows has two components. On the one hand, there are "exogenous" separations, given by the product of the separation rate, $s$, with the current number of employees $N_{i, j, t}$. On the other hand, firms adopt an active firing policy, denoted by $F_{i, j, t}$.

At the firm level, firing costs depend on the firing level $F_{i, j, t}$. These firing costs generalize the simple case exposed in Pissarides [1986]. Firing costs are defined by the function: $\phi\left(F_{i, j, t}\right): \mathbb{R}_{+} \longrightarrow \mathbb{R}_{+}$, strictly increasing and convex. We impose $\phi(0)=0$ and $\lim _{F_{i, j, t} \rightarrow(1-s) N_{j, t}} \phi\left(F_{i, j, t}\right)=\infty$. Given that all the firms of the sector have the same employment at the beginning of the period $\left(N_{i, j, t}=N_{j, t} \forall i\right)$, this condition simply account for the rise of the reorganization cost as firms fire. ${ }^{5}$

\footnotetext{
${ }^{4}$ Unemployed workers find jobs more easily as the number of vacancies is high relatively to the number of workers involved in the matching process; symmetrically, the greater the number of searching workers is, the easier it is for a firm to fill up a vacancy.

${ }^{5}$ This assumption guarantees that firing will never rise up to the point where employment becomes zero.
} 
In sector $j$, employment evolves according to the following law of motion:

$$
N_{j, t+1}=(1-s) N_{j, t}+H_{j, t}-F_{j, t}
$$

Thus, productive employment at time $t+1$ is hired at time $t$, implying some labor hoarding phenomenon. Therefore, the number of unemployed is an adjustment variable. However, the aggregate job availability only determines the rate at which jobs vacancies are filled. This externality causes a stochastic rationing on the individual hiring policy.

It is worth noting at this point that when the firm hires, it has to go on the labor market in order to find a worker. In this case it faces aggregate trade externalities. Conversely, when the firm fires, it does not face aggregate trade externalities.

\subsection{Individual decision rules}

The dynamic problem of the firm $i$ is to decide the number of vacancies $V_{i, j, t}$ and firings $F_{i, j, t}$ so as to maximize the expected discounted sum of profit flows:

$$
\max _{\left\{V_{i, j, t+\tau}, F_{i, j, t+\tau}\right\}_{\tau=0}^{\infty}} E_{t}\left\{\sum_{\tau=0}^{\infty}(1+r)^{-\tau}\left[\Pi_{i, j, t+\tau}-\psi\left(V_{i, j, t+\tau}\right)-\phi\left(F_{i, j, t+\tau}\right)\right]\right\}
$$

subject to

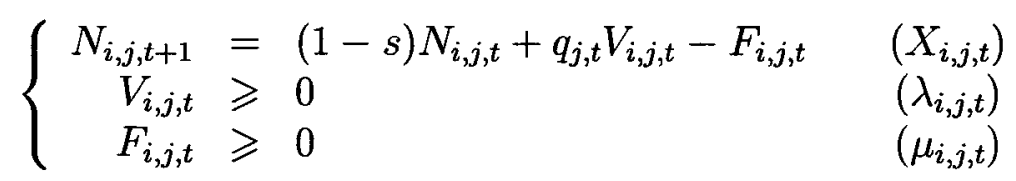

where $(1+r)^{-1}$ denotes the firm's discount factor, $r \in(0,1) . \quad \lambda_{i, j, t}$ and $\mu_{i, j, t}$ are the Lagrange multipliers associated to the positivity constraints on respectively vacancies and firings. $X_{i, j, t}$ can be interpreted as the marginal valuation of employment. $\Pi_{i, j, t}$ is the operating profit flow of the firm $i$ at time $t$ in sector $j$, given the real wage $w_{i, j, t}$ :

$$
\Pi_{i, j, t}=\left((1+\kappa) \bar{a}+\eta_{j, t}\right) N_{i, j, t}-w_{i, j, t} N_{i, j, t}
$$

Note that instantaneous operating profits are linearly homogeneous in employment. The first-order conditions for a firm $i$ shows that firm posts vacancies up to the point where the marginal value of a vacancy equals its marginal cost:

$$
-\psi^{\prime}\left(V_{i, j, t}\right)+X_{i, j, t} q_{j, t}+\lambda_{i, j, t}=0
$$


This optimality condition is equivalent to the standard "free entry" condition in the labor market when firms can have only one job - filled or unfilled. Concerning firings, the optimality condition states that firms fire up to the point where the marginal value of employment is equal to the marginal cost of firings:

$$
-\phi^{\prime}\left(F_{i, j, t}\right)-X_{i, j, t}+\mu_{i, j, t}=0
$$

We also have the two additional conditions:

$$
\begin{aligned}
& \lambda_{i, j, t} V_{i, j, t}=0 \\
& \mu_{i, j, t} F_{i, j, t}=0
\end{aligned}
$$

From the first order conditions (4)-(5) together with (6) and (7), for any given value of $X_{i, j, t}$, we get the following property.

Proposition 1 A firm will not fire when it has positive vacancies. Conversely, a firm will not post any vacancy when it fires.

PRoOf: See Appendix A.

According to equations (4)-(5) and proposition 1, a firm posts vacancies and does not fire when the expected marginal value of employment is greater than the marginal cost of posting no vacancy - i.e. $\psi^{\prime}(0) / q_{j, t}$. Further, the firm posts no vacancies and fires when the expected marginal value of employment is negative and less than minus the marginal cost of firing, when firings are zero - i.e. $-\phi^{\prime}(0)$. There exists a third regime, characterized by a marginal value lying between the two last values, in which firms are totally inactive: they neither fire nor post vacancies.

\subsection{Equilibrium decision rules}

In order to compute the equilibrium on the labor market, we specify first the wage setting rule. We assume that each firm acts as a monopsonist in the labor market. Hence, firm set the real wage at the instantaneous gain of an unemployed worker - 
i.e. unemployment benefits. As workers are perfectly mobile, the reservation wage is the same across sectors. Finally, we assume that it is indexed on aggregate productivity such that $w_{i, j, t}=\kappa \bar{a} .^{6}$

The symmetric equilibrium in sector $j$ is defined by a set of functions $\left\{V_{j}(),. F_{j}(),. N_{j}().\right\}$ which depends on the information set $\mathcal{I}_{t}{ }^{7}$ Thus, $V_{j, t}=V_{j}\left(\mathcal{I}_{t}\right), F_{j, t}=F_{j}\left(\mathcal{I}_{t}\right)$ and $N_{j, t+1}=N_{j}\left(\mathcal{I}_{t}\right)$ solve:

$$
\begin{array}{cll}
\psi^{\prime}\left(V_{i, j, t}\right)=q_{j, t} X_{i, j, t} & \text { if } \quad X_{i, j, t}>\psi^{\prime}(0) / q_{j, t} \\
V_{i, j, t}=F_{i, j, t}=0 & \text { if } \quad-\phi^{\prime}(0) \leqslant X_{i, j, t} \leqslant \psi^{\prime}(0) / q_{j, t} \\
-\phi^{\prime}\left(F_{i, j, t}\right)=X_{i, j, t} \quad \text { if } & X_{i, j, t}<-\phi^{\prime}(0) \\
V_{j, t}=\int_{0}^{1} V_{i, j, t} \mathrm{~d} i & \\
F_{j, t}=\int_{0}^{1} F_{i, j, t} \mathrm{~d} i
\end{array}
$$

As our economy displays constant returns to scale, the marginal value of employment corresponds to its average value and satisfies the following property.

Proposition 2 At a sectoral symmetric equilibrium, marginal value of employment is exogenous.

Proof: See Appendix A.

We thus get:

$$
\begin{aligned}
X_{j, t} & =\frac{1}{1+r} E_{t}\left[\bar{a}+\eta_{j, t+1}+(1-s) X_{j, t+1}\right] \\
N_{j, t+1} & =(1-s) N_{j, t}+q_{j, t} V_{j, t}-F_{j, t}
\end{aligned}
$$

Equation (8) gives the level of hiring, while equation (10) furnishes the firing level both in terms of $X_{j, t}$. As aforementioned the model displays three regimes. The shift from one regime to another is driven by the shocks, as implied by proposition 2. Marginal value of employment results from changes in sectoral technology. Thus when a negative shock occurs in a given sector, the marginal valuation of employment decreases, and

\footnotetext{
${ }^{6}$ Note that $\kappa$ will drop out from the profit flow.

${ }^{7}$ We denote $\mathcal{I}_{t}=\left\{N_{t},\left\{\eta_{j, t}\right\}_{j=1}^{S}\right\}$, where $S$ denotes the number of sectors.
} 
can reach a level lower than the bound that renders a firing policy worth to implement. In this situation, the equalization of marginal value of employment to the marginal cost of firings implies that firings shift up. In the case of a positive shock, the increase in the marginal value of employment leads firms to post vacancies, which are determined by the equalization of marginal value of employment to marginal cost of posting vacancies. In the third regime, firms will neither hire nor fire. Employment will decrease at a constant rate, determined by the exogenous quit rate. As shown by proposition 1, hirings and firings cannot coexist at the sectoral level. Nevertheless, as we consider a multi-sector economy, hirings and firings will coexist at the aggregate level, because each sector experiences a specific history of productivity shocks. Heterogeneity is thus a necessary condition to study aggregate creation and destruction rates.

\section{Estimation and Testing}

This section is devoted to the exposition of estimating strategy and associated inference. We first present our specification choices.

\subsection{Specification}

In the lines of the standard literature on matching process, the matching technology is assumed to be represented by a Cobb-Douglas function:

$$
H_{j, t}=\bar{H} V_{j, t}^{\alpha} U_{t}^{1-\alpha}
$$

where $\alpha \in(0,1)$ and $\bar{H}>0$. The costs of posting vacancies are given by:

$$
\psi\left(V_{i, j, t}\right)=\frac{\omega}{2} \frac{V_{i, j, t}^{2}}{V_{j, t}}
$$

It is worth noting that at the individual level, the marginal cost of posting vacancies is zero when $V_{i, j, t}=0$. This modelling thus has the advantage to yield the same reduced form as the standard vacancy cost setup in the symmetric equilibrium.

In order to preserve homogeneity of firing costs at the sectoral level, firing costs are supposed to be more important if the number of firings in a firm is large relatively to 
the net employment of the sector $(1-s) N_{j, t}$. Then, firing cost function depends on an external effect and is given by:

$$
\phi\left(F_{i, j, t}\right)=\varphi \frac{F_{i, j, t}^{2}}{(1-s) N_{j, t}-F_{i, j, t}}
$$

This specification implies that at symmetric equilibrium the marginal cost of firings will be zero whenever the firings are zero. The third regime is thus reduced to a unique point. As its occurrence is conditional on a random variable distributed on a continuous support, its probability of occurrence is reduced to zero. This particular form for the adjustment cost have the appealing feature that it allows for sudden and large changes in firings, while warranting positive employment. Indeed at symmetric equilibrium, as firings approach $(1-s) N_{j, t}$ by above, the cost of firings tends to infinity.

Given these specifications, in each and every period, the realization of the shocks gives a particular value at $X_{j, t}$, implying the following specific decision rules:

- If $X_{j, t}>0$, then $V_{j, t}>0$. In this case, the hiring function in equilibrium can be written:

$$
H\left(X_{j, t}, N_{t}\right)=\bar{H}^{\frac{1}{1-\alpha}} \omega^{\frac{\alpha}{\alpha-1}} X_{j, t}^{\frac{\alpha}{1-\alpha}}\left(1-N_{t}\right)
$$

This hiring function explicitly shows that the state of the labor market - the unemployment rate $\left(U_{t}=1-N_{t}\right)$ - affects the individual decision rules.

- if $X_{j, t}=0$, then $V_{j, t}=F_{j, t}=0$, i.e. firms of the sector $j$ let the level of employment decrease at the exogenous quit rate $s$.

- if $X_{j, t}<0$, then $F_{j, t}>0$. In this case, firms decide actively to fire workers. The equilibrium firing rate function is given by:

$$
F\left(X_{j, t}\right)=(1-s) N_{j, t}\left[1-\left(\frac{\varphi-X_{j, t}}{\varphi}\right)^{-1 / 2}\right]
$$

At symmetric sectorial equilibrium, the level of firing is a fraction of net employment in sector $\mathrm{j}(1-s) N_{j, t}$, fraction depending negatively on the marginal value of employment. 
Given the process of the shock (2), the dynamics of aggregate employment can be summarized as

$$
\left\{\begin{aligned}
N_{j, t+1} & =(1-s) N_{j, t}+\mathbb{1}_{\left[X_{j, t}>0\right]} H\left(X_{j, t}, N_{t}\right)-\mathbb{1}_{\left[X_{j, t}<0\right]} F\left(X_{j, t}\right) \\
X_{j, t} & =\alpha_{0}+\alpha_{1} \eta_{j, t} \\
N_{t} & =\sum_{j=1}^{S} \gamma_{j} N_{j, t} \text { with } \sum_{j=1}^{S} \gamma_{j}=1
\end{aligned}\right.
$$

where the weight $\gamma_{j}$ is the share of sector $j$ employment in aggregate employment. ${ }^{8} \alpha_{0}$ and $\alpha_{1}$ are non-linear functions of the deep parameters. ${ }^{9} \mathbb{1}_{[z]}=1$ when $z$ is true, 0 otherwise. Employment dynamics is thus characterized by the presence of a dynamic latent variable, $X_{j, t}$, that determines the shift between regimes along the business cycle.

\subsection{Estimation Method}

We are interested in the aggregate implications of our structural model. Non-linearities and difficulties occur from various sources. First, aggregate externalities appear in employment dynamics at the sectoral level. Second, both creation and destruction levels are non-linear policy functions (see system based equations (15)). Third, these series are aggregated over sectors. Fourth, we compute gross job creation and destruction rate deflated by the average of begin and end of period stocks. This normalization is performed to insure compatibility of aggregate data. ${ }^{10}$ These various elements lead also to complicated reduced forms for aggregate creation and destruction rates, which thus imply an intractable likelihood functions and/or moments that cannot be computed using direct integration methods. This implies that neither maximum likelihood nor GMM can be implemented in this framework. In order to circumvent these difficulties, we implement a simulation-based estimation and testing method (See e.g. Gallant and Tauchen [1996], Gouriéroux et al. [1993] and Smith [1993]).

Here, we adopt an indirect inference method, which has the advantage to be easily implementable even when the structural model is complicated. The choice of an auxiliary model (or auxiliary parameters) is an important step for this simulation based

\footnotetext{
${ }^{8}$ These shares may be interpreted as reflecting the structure of preferences for the different goods produced in the economy. As we focus on the labor market dynamics, we do not provide any further foundation to these weights and left them exogenous.

${ }^{9}$ The exact form of these parameters is given in appendix Appendix A.

${ }^{10}$ Simulated data are built in accordance with Davis and al.'s definition.
} 
estimation method. In order to avoid this arbitrary choice and to reduce biases in estimation (see Michaelides and $\mathrm{Ng}$ [1997]), we use moments and other descriptive statistics that encompass as many features of the data as possible. Because our model suggests potential non-linearities, moments on aggregate gross job creation and destruction rates should account for this pattern. Thus, the set of moments combines usual moments (sample mean, variance and correlation) and higher order moments to match asymmetric behavior of the data. The auxiliary parameters are the following:

$$
\psi_{t}=\left\{m_{1}\left(x_{t}\right), \mu_{i}\left(x_{t}\right), \operatorname{med}\left(x_{t}\right), \rho\left(x_{t}\right), \operatorname{corr}\left(c_{t}, d_{t}\right), \tau_{0}, \tau_{1}\right\}
$$

where $x_{t}=\left\{c_{t}, d_{t}\right\} . c_{t}$ is the aggregate creation rate and $d_{t}$ is the aggregate destruction rate. $m_{1}\left(x_{t}\right)=E\left(x_{t}\right)$ and $\mu_{i}\left(x_{t}\right)=E\left[\left(x_{t}-m_{1}\left(x_{t}\right)\right)^{i}\right], i=2, \cdots, 4, \operatorname{med}\left(x_{t}\right)$ denotes the median and $\rho\left(x_{t}\right)$ is the first order autocorrelation. The parameters $\tau_{0}$ and $\tau_{1}$ are associated to a simple parametric model, that matches some potential asymmetries in gross job creation and destruction rates. The first moments are rather conventional, that is the sample mean $\left(m_{1}().\right)$ and variance $\left(\mu_{2}()=.\sigma .^{2}\right)$ of the data. We introduce higher order moments in order to capture some non-linear properties of the data. For example, significant third moments indicate departure from normality. Moreover, the normality assumption implies linear relationships between even order moments. ${ }^{11}$ In order to compare our results with previous findings, we introduce the linear correlation between gross creation and destruction rate $\left(\operatorname{corr}\left(c_{t}, d_{t}\right)\right)$ and autocorrelations. Nevertheless, potential non-linearities must not be ignored. We thus introduce the regression equation $c_{t}=\tau_{0}+\tau_{1} / d_{t}$. This equation allows to capture the non-linear correlation between creation and destruction. A positive value for $\tau_{1}$ implies a larger correlation between creations and destruction when the destruction rate is low. Thus, these two conditional moments show that the effect of job destructions on job creations depends crucially on the level of destruction rates - i.e. the state of the business cycle on the labor market. Further, we also report medians in order to show potential departure from symmetry. The auxiliary parameters are thus estimated minimizing the following

\footnotetext{
${ }^{11}$ For example, a significant moment of order three implies skewness, while $\mu_{4} / \mu_{2}^{2} \neq 3$ implies kurtosis.
} 
loss function:

$$
Q_{T}=\left[\frac{1}{T} \sum_{t=1}^{T} g_{t}\left(\psi_{T}\right)\right]^{\prime} \Omega_{T}\left[\frac{1}{T} \sum_{t=1}^{T} g_{t}\left(\psi_{T}\right)\right]
$$

where $\Omega_{T}$ is definite positive weighting matrix. $g_{t}($.$) is defined as follows: { }^{12}$

$$
g_{t}\left(\psi_{T}\right) \equiv\left[\begin{array}{c}
m_{1}(x)-x_{t} \\
\left(x_{t}-m_{1}(x)\right)^{i}-\mu_{i}(x) \\
\left|x_{t}-\operatorname{med}(x)\right| \\
\left(x_{t}-m_{1}(x)\right)\left(x_{t-1}-m_{1}(x)\right)-\rho(x) \mu_{2}(x) \\
\left(c_{t}-m_{1}(c)\right)\left(d_{t}-m_{1}(d)\right)-\operatorname{corr}(c, d)\left(\mu_{2}(c) \mu_{2}(d)\right)^{1 / 2} \\
c_{t}-\tau_{0}-\tau_{1} / d_{t} \\
\left(c_{t}-\tau_{0}-\tau_{1} / d_{t}\right) \cdot\left(1 / d_{t}\right)
\end{array}\right] \quad \begin{aligned}
& i=2, \cdots, 4 \\
& x \in\{c, d\}
\end{aligned}
$$

We thus consider 15 auxiliary parameters, which allow to estimate the unknown structural parameters $\theta=\{\alpha, r, s, \bar{H}, \omega, \varphi, \bar{a}, \rho, \sigma\}$ and to conduct some specification tests.

The basic idea of indirect inference ${ }^{13}$ is to find the vector of structural parameters, $\widetilde{\theta}_{T}^{N}$, which minimizes the following loss function:

$$
J(\theta)=g_{T, N}^{\prime} W_{T} g_{T, N}
$$

with $g_{T, N}=\left(\widehat{\psi}_{T}-\frac{1}{N} \sum_{i=1}^{N} \tilde{\psi}_{T}^{i}(\theta)\right) . \quad N$ denotes the number of simulations used for estimation and $W_{T}$ is a definite positive covariance matrix, which depends on the data. $\widehat{\psi}_{T}$ corresponds to the value of $\psi$ which minimizes $Q_{T}$ from the observed data $\left\{c_{t}, d_{t}\right\}_{t=1}^{T}$, while $\widetilde{\psi}_{T}^{i}(\theta)$ corresponds to the value of $\psi$ which minimizes $Q_{T}$ from the simulated data $\left\{c_{t}^{i}, d_{t}^{i}\right\}_{t=1}^{T}$ for $i=1, \cdots, N$ for a given value of $\theta$.

Identifying conditions impose that the number of moments exceeds the number of structural parameters. Thus, one may conduct a global specification test, denoted $J$-stat $=T N J(\theta) /(1+N)$ at convergence. This statistic is distributed as a chi-square, with a degree of freedom equal to the number of over-identifying conditions. ${ }^{14}$

We further develop a simple diagnostic test, in the lines of Gallant et al. [1994] (in the case of simulated score), to locate the potential failures of the structural model. The main idea is that each element of $g_{T, N}$ measures the discrepancy between the moments computed from the data and from model simulations. Each element thus contains a

\footnotetext{
${ }^{12}$ Note that moments of order 3 and 4 were pre-multiplied by $1 e 6$ and $1 e 7$.

${ }^{13}$ See Appendix $B$ for a complete statement of the indirect inference implementation.

${ }^{14}$ The indirect inference also allows for indirect tests of hypothesis on the parameters of interest $\theta$.
} 
diagnostic information assessing the ability of the model to match each moments. A small value for some elements indicates that the structural model is able to well explain some features of the data, while large values may reveal some failure. The first order condition associated to the minimization of the loss function $J(\theta)$ leads to:

$$
\left.D_{\theta}^{\prime} W_{T} g_{T, N}\right|_{\theta=\tilde{\theta}_{T}^{N}}=0
$$

where $D_{\theta}=\partial g_{T, N} / \partial \theta$. Let denote $\psi_{0}$ is the pseudo-true value of $\psi$ and $\theta_{0}$ is the pseudo-true value of $\theta$. Using the mean value approximation of $g_{T, N}$,

$$
g_{T, N} \simeq\left(\widehat{\psi}_{T}-\psi_{0}\right)+D_{\theta}\left(\theta_{T}^{N}-\theta_{0}\right)
$$

we get

$$
\sqrt{T}\left(\widetilde{\theta}_{T}^{N}-\theta_{0}\right) \simeq-\left(D_{\theta}^{\prime} W_{T} D_{\theta}\right)^{-1} D_{\theta}^{\prime} W_{T} \sqrt{T}\left(\widehat{\psi}_{T}-\psi_{0}\right)
$$

Plugging the latter expression into the mean value approximation and pre-multiplying both sides by $\sqrt{T}$, one gets:

$$
\sqrt{T} g_{T, N} \simeq\left(I_{q}-D_{\theta}\left(D_{\theta}^{\prime} W_{T} D_{\theta}\right)^{-1} D_{\theta}^{\prime} W_{T}\right) \sqrt{T}\left(\widehat{\psi}_{T}-\psi_{0}\right)
$$

Now, using the fact that the auxiliary parameters are normally distributed:

$$
\sqrt{T}\left(\widehat{\psi}_{T}-\psi_{0}\right) \simeq \Omega_{T}^{1 / 2} \vartheta \quad \vartheta \sim \mathcal{N}\left(0, I_{q}\right)
$$

and that the optimal weighting matrix corresponds to the inverse of the covariance matrix $\Omega_{T}$, one obtains after some algebra

$$
\sqrt{T} g_{T, N} \sim \mathcal{N}\left(0, \Omega_{T}-D_{\theta}\left(D_{\theta}^{\prime} W_{T} D_{\theta}\right)^{-1} D_{\theta}^{\prime}\right)
$$

Thus, each element of the following vector of $t$-statistics:

$$
T_{T, N}=\left\{\operatorname{diag}\left[\Omega_{T}-D_{\theta}\left(D_{\theta}^{\prime} W_{T} D_{\theta}\right)^{-1} D_{\theta}^{\prime}\right]\right\}^{-1 / 2} \sqrt{T} g_{T, N}
$$

is asymptotically $\mathcal{N}(0,1)$. The test statistics is computed replacing $D_{\theta}$ and $\Omega_{T}$ by consistent estimates. 


\section{Empirical Results}

This section first presents the data, before turning to the exposition of empirical results.

\subsection{The Data}

The data, provided by J. Haltiwanger, are fully described in Davis et al. [1996]'s monograph. In this study, our attention is restricted to aggregate manufacturing job flows. Finally, the sample runs from the second quarter of 1972 to the fourth quarter of 1988.

Figure 1: US Aggregate Job Flows
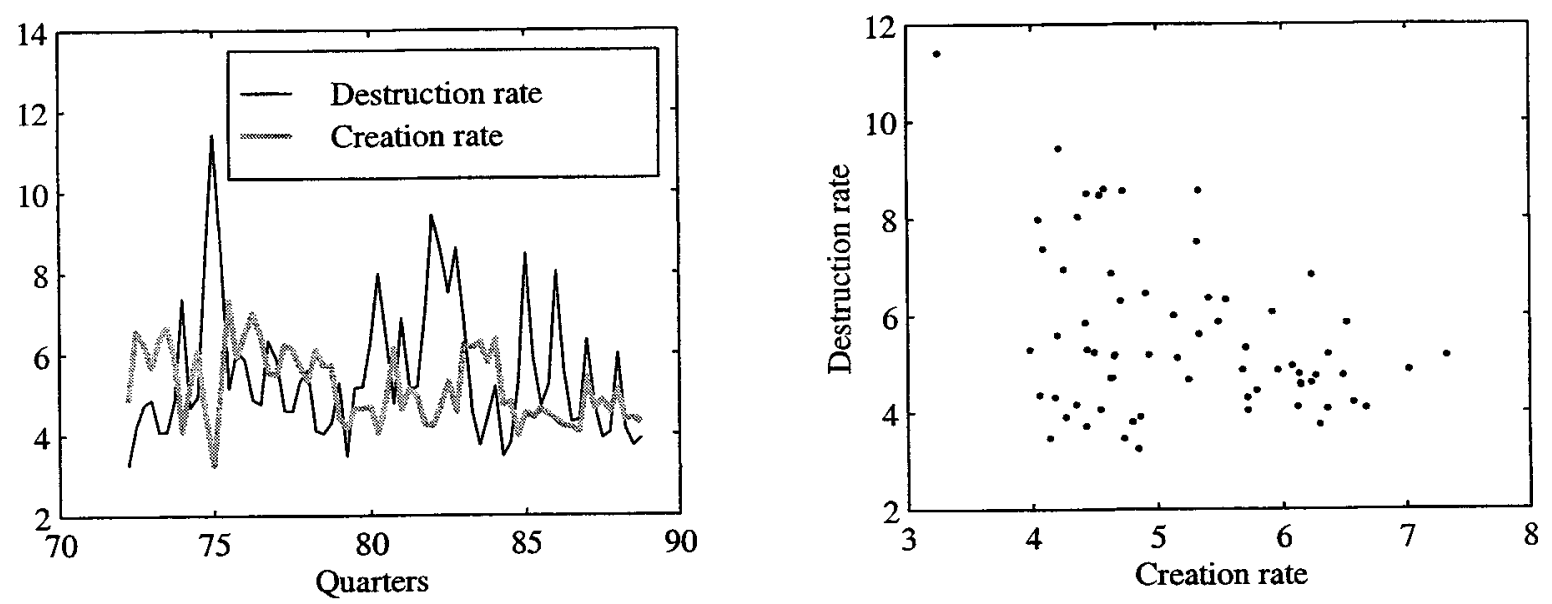

First of all, it appears that the magnitude of gross flows is large in the US economy, $10.7 \%$ of jobs were reallocated on average each quarter within the sample period. Further, gross creation rate is lower on average than gross destruction rate, indicating that the US economy rather destroyed jobs than it created on average. What is even more striking is the high volatility of job flows. Further, the destruction rate is $78 \%$ more volatile than the creation rate. Plots of job creation and destruction rates illustrate these features (see figure 1).

While creation do not display that much asymmetries, destruction displays both significant skewness and excess kurtosis (see table 1). Further, median differs from mean in both cases. Nevertheless the discrepancy between mean and median is a bit more pronounced for destruction, indicating a slightly higher degree of asymmetry. These features of aggregate gross job flows indicate that both recessions and expansions differ 
in their implications in terms of hiring-firing decisions. Actually, while creation will react in quite the same way in expansion and recession, the jobs destruction dynamics will be asymmetric.

Table 1: Selected moments on US job Flows

\begin{tabular}{ccc}
\hline \hline & Creation rate & Destruction rate \\
\hline$m_{1}\left(x_{t}\right)$ & 5.2063 & 5.5691 \\
& $(0.1998)$ & $(0.3043)$ \\
$\mu_{2}\left(x_{t}\right)^{1 / 2}$ & 0.8930 & 1.6345 \\
& $(0.0801)$ & $(0.2041)$ \\
$\mu_{3}\left(x_{t}\right)$ & 20.1198 & 544.4040 \\
& $(24.7326)$ & $(209.2290)$ \\
$\mu_{4}\left(x_{t}\right)$ & 13.5704 & 307.7230 \\
& $(5.1368)$ & $(138.9780)$ \\
$\operatorname{med}\left(x_{t}\right)$ & 4.9336 & 5.1552 \\
& $(0.1855)$ & $(0.2597)$ \\
$\rho\left(x_{t}\right)$ & 0.5427 & 0.5354 \\
& $(0.0841)$ & $(0.0819)$ \\
\hline $\operatorname{corr}\left(c_{t}, d_{t}\right)$ & \multicolumn{2}{c}{-0.3704} \\
& \multicolumn{2}{c}{$(0.1441)$} \\
$\tau_{0}$ & \multicolumn{2}{c}{4.2180} \\
$\tau_{1}$ & \multicolumn{2}{c}{$0.05004)$} \\
& \multicolumn{2}{c}{$(0.0309)$} \\
\hline \hline
\end{tabular}

Note: All moments, except correlations, are multiplied by 100 .Moments are obtained minimizing $Q_{T}$. Estimates are robust to both heteroskedasticity and serial correlation. We used a Parzen window with bandwidth parameter set to 10 .

Finally, the bottom of table 1 provides some insights on the joint behavior of job flows within the business cycle. More specifically, creations and destructions are negatively correlated. They are thus in opposite phase within the business cycle. Indeed, as it is now well-known, job creation is procyclical whereas job destruction is strongly countercyclical. The estimated values of $\tau_{0}$ and $\tau_{1}$ predict that the lower is the destruction rate, the higher is the correlation between creations and destructions. The model shed light on this result. Assume for a while that the economy is at a peak, so that creations are high whereas destruction rate is low. In this situation, given the level of 
the threshold deciding the shift to the firing regime, the majority of firms are posting vacancies but are in a neighborhood of the threshold. Assume now that a negative shock occurs in a great number of sectors. Then, a lot of firms shift to the firing regime, and there is a drop in creation rate. Thus correlation between creation and destruction rates is strongly negative. Now assume that, on the contrary, the destruction rate is high, and that the majority of firms fires. Given the persistence of shocks, even if a negative shock occurs, only a few number of firms will shift back to the hiring regime. Then, in the case of a small decrease in the destruction rate, creation will not increase that much. Thus, the correlation between creation and destruction rates is rather weak. These features actually illustrate the non-linear shape of the relationship between creation and destruction rates that our simple auxiliary model illustrated. High creation rates are associated with low destruction rate and vice-versa. Furthermore, this tells us that creations are procyclical whereas destructions are countercyclical.

\subsection{Estimation Results}

We do not estimate all the structural parameters. Some of them are fixed because identification problems occurred during estimation. ${ }^{15}$ We first set the number of sectors to 20 , in accordance with the first level of disaggregation in Haltiwanger's dataset. We thought of this disaggregation level as the critical, although arbitrary, level that permits to obtain sufficient heterogeneity in the model. As we are interested in showing that intersectoral reallocation - through aggregate trade externalities - is a sufficient mechanism to account for aggregate job flows dynamics, we choose to discard intrasectoral reallocation. Setting the number of sectors to 20 allows to protect our statistical inference from such phenomena. The vector of employment weights, $\left\{\gamma_{j}\right\}_{j=1}^{S}$, is set to its empirical counterpart (see table 2).

The discount factor is constrained at $1 \%$ per quarter. $\bar{H}$ and $\omega$ are not identifiable, we thus set $\xi=\bar{H}^{1 /(1-\alpha)} \omega^{\alpha /(\alpha-1)}$ to a value which allows to match the profile of participation rate in the US economy. We will thus estimate the parameters for (i) the process of shocks $(\rho, \sigma)$, (ii) the level of technology $(\bar{a})$, (iii) creation process $(\alpha)$ and (iv) the

\footnotetext{
${ }^{15}$ See Appendix $\mathrm{B}$ for further details on implementation of indirect inference.
} 
Table 2: Sectoral employment weights (in percents)

\begin{tabular}{lclc}
\hline \hline Food & 8.16 & Rubber & 4.21 \\
Tobacco & 0.36 & Leather & 1.39 \\
Textile & 5.35 & Stone, Clay and Glass & 3.39 \\
Apparel & 7.76 & Primary metals & 5.96 \\
Lumber & 4.13 & Fabricated metals & 8.70 \\
Furniture & 2.85 & Non-electric machinery & 10.28 \\
Paper & 3.76 & Electric machinery & 9.22 \\
Printing & 5.20 & Transportation & 9.49 \\
Chemicals & 3.95 & Instruments & 2.83 \\
Petroleum & 0.72 & Miscellaneous & 2.29 \\
\hline \hline
\end{tabular}

firing process ( $\varphi$ and $s$ ). Because we adopt a parsimonious approach to the aggregate implications of heterogeneity, we do not introduce behavioral heterogeneity, except in the realization of the specific sectoral shock. ${ }^{16}$ Despite its simplicity, this approach allows to model heterogeneity without introducing a large number of parameters.

The minimization of the simulated criterion function is carried out using a simplex method for minimization provided in the Optim MATLAB numerical optimization toolbox. We prefer this method to more traditional optimizers that use local gradient search methods, as they fail to converge in our experiments. We use 20 simulations for a sample size equals to 67 . Simulated values are redrawn from the same seed values for each evaluation function. Simulation experiments of Michaelides and Ng [1997] indicates that efficiency gain becomes negligible when the number of simulations exceeds ten. In order to reduce the effects of initial conditions, simulated samples includes 250 initial points which are subsequently discarded in the estimation. The initial condition corresponds to the sectoral steady-state value of employment.

Table 3 reports estimates of structural parameters.

Parameter estimates are all both precisely estimated and economically meaningful. The quit rate is around $3.9 \%$ per quarter. This value for the exogenous quit rate is rather low compared to previous estimates. Nevertheless, as the model incorporates

\footnotetext{
${ }^{16}$ We thus consider what Caballero and Engel [1991] call stochastic heterogeneity rather than structural heterogeneity which would amount to consider specific sectoral behavior.
} 
Table 3: Parameter estimates

\begin{tabular}{ccccccc}
\hline \hline$\rho$ & $\sigma$ & $\bar{a}$ & $s$ & $\alpha$ & $\varphi$ & J-stat \\
\hline 0.7289 & 0.0029 & 0.0006 & 0.0388 & 0.3618 & 0.0109 & 12.65 \\
$(0.0459)$ & $(0.0009)$ & $(0.0002)$ & $(0.0019)$ & $(0.0916)$ & $(0.0026)$ & {$[18]$} \\
\hline \hline
\end{tabular}

Note: standard errors in parentheses, p-values (\%) into brackets

endogenous firings, the exogenous quit rate $s$ only accounts for part of the separation process. The estimated value for $\alpha$ appears to be smaller than the one obtained in previous estimates of the matching function (see e.g. Blanchard and Diamond [1989]). This can be explained by the fact that (i) we do not rely on the same information set and (ii) contrary to previous studies our estimation is model dependent. However, a Wald test cannot reject the restriction $\alpha=0.5$, obtained by previous studies.

Figure 2: Diagnostic Test

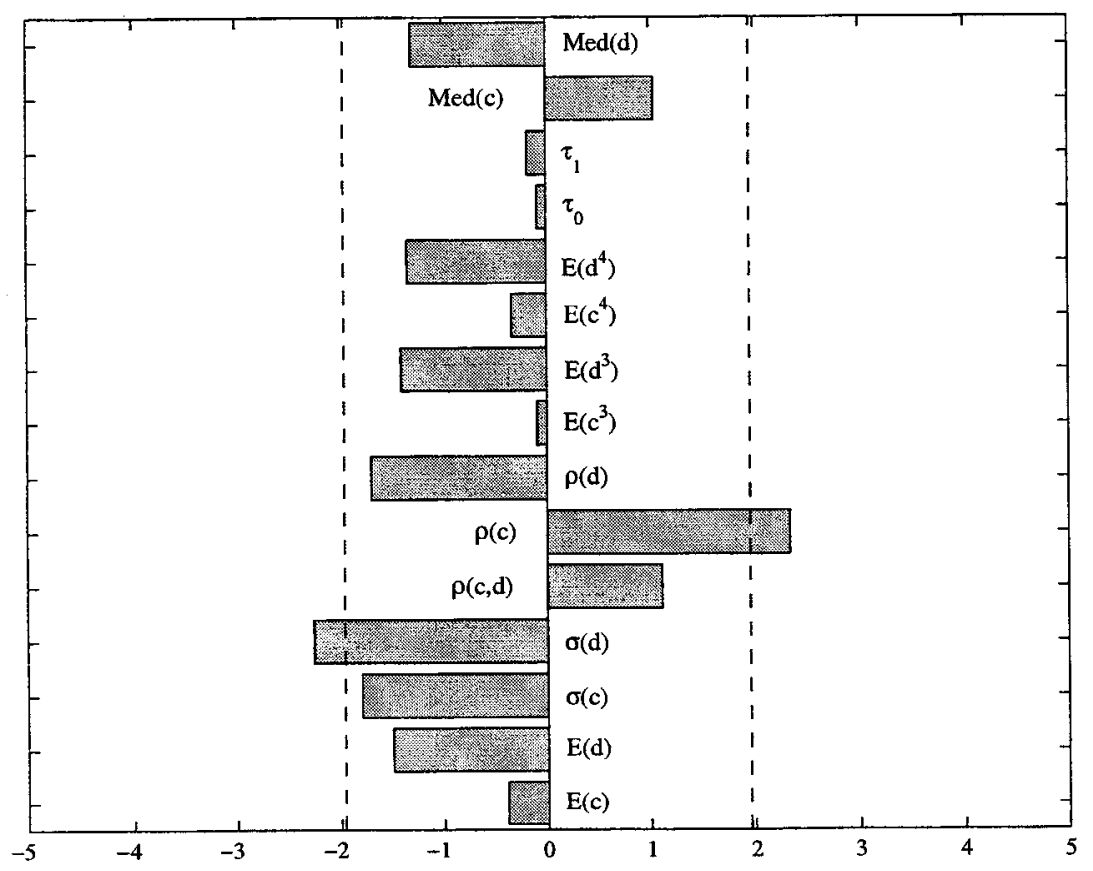

Note: a positive value of the statistics indicates an over-estimation whereas a negative value indicates an under-estimation. The statistics is distributed as a $\mathcal{N}(0,1)$. Dashed line represents the confidence interval at the $95 \%$ level.

Beyond the estimated values of the structural parameters, one may look at the 
diagnostic test, in order to locate where the model performs or fails. A positive value for the statistics indicates an over-estimation of the considered moment whereas a negative value indicates an under-estimation. This diagnostic test contains the same information than the comparison between simulated and actual moments, in that it furnishes a measure of the discrepancy between empirical and theoretical moments. In accordance with the global specification test, the diagnostic test suggests that the model matches well most of the moments under consideration. However, it still overestimates the persistence of creations and underestimates the volatility of destructions. This suggests - without questioning the global significance of the model - further improvements in the modelling of job flows. Given the good statistical properties of the model, we report in figure 3 kernel estimates of the unconditional density of aggregate creation and destruction rates. This figure shows that the unconditional density generated by the model does not differ that much from the one obtained from actual data. This also illustrates the departure from normality for the data, and especially for the destruction rate.

Figure 3: Kernel estimates of unconditional densities
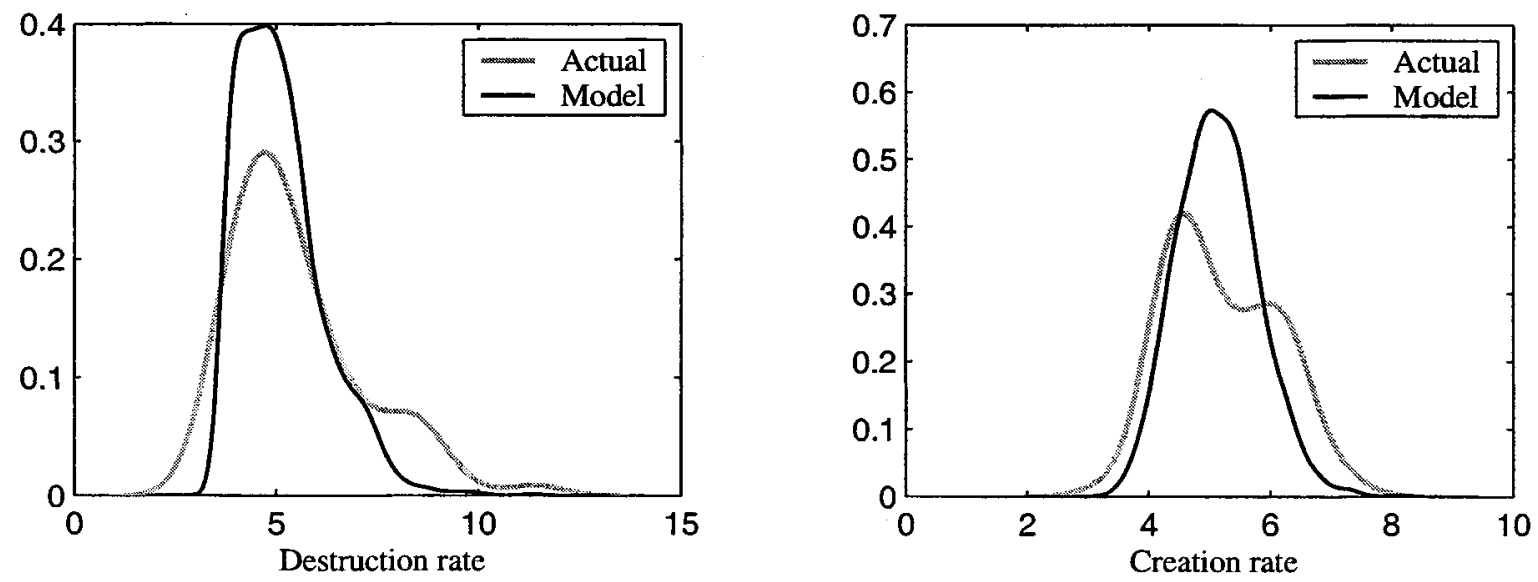

As indicated by the previous results, the model furnishes a good approximation of the actual Data Generating Process. The model may constitute a useful tool to understand of propagation mechanisms at work in the determination of creations and destructions within the business cycle as well as potential asymmetries displayed by the data. 


\subsection{Propagation mechanisms}

We now turn to the analysis of qualitative dynamic properties of the model through various impulse response functions (IRF) experiments on aggregate creation and destruction rates. This supplements the preceding analysis, in that it allows not only to locate but also to characterize the form of asymmetries. The non-linearity displayed by the model leads us to adopt the more general approach described by Koop, Pesaran and Potter [1996]. It is worth noting that IRF profiles are strongly conditional on both the sign and the size of the shock, but also the initial employment level. Koop et al. [1996] argue that these dimensions should be explored simultaneously. In our case, and for benchmark purposes, we only report IRF around the sample mean of simulated employment. ${ }^{17}$

A shock in a given sector leads to very different patterns depending on both the size and the sign of the shock. Asymmetries occur even for small shocks (a standard deviation shock). As shown in figure $4, \mathrm{IRF}$ on destruction rates display a higher degree of asymmetry than that on creation rates, whatever the sector in which the shock occurs. The magnitude of the response of destruction rate to a negative shock is higher than that of the response of creation rate. This thus explains the asymmetries displayed in the distribution of creation and destruction rates. Firms increase their firings by more in response to a negative sectoral shock than it would decrease in face of a positive sectoral shock of the same magnitude. Further, as the model displays global constant returns to scale, IRF are defined up to a scaling factor. This implies that IRF following a shock in a small sector will be proportional to the one in a big sector. This scaling factor is given by the relative weight of the sector. ${ }^{18}$

Figure 5 finally reports IRF for different sizes of the sectoral shock. ${ }^{19}$ As in the previous experiments, IRF of creation rate do not display that much asymmetries.

\footnotetext{
${ }^{17}$ See appendix Appendix $\mathrm{C}$ for computational issues. IRF were obtained using Monte Carlo integration conducted with 5000 replications.

${ }^{18}$ For instance, if we consider the smallest and the biggest sector of the sample under study, $I R F_{\text {Big sector }}=(10.28 / 0.36) \times I R F_{\text {Small sector }}$ (See figure 4$)$.

${ }^{19}$ Because of the homothetic property the model generates, we only report IRF for aggregate data following a shock in a big sector.
} 
Figure 4: IRF to positive versus negative sectoral shocks Big Sector
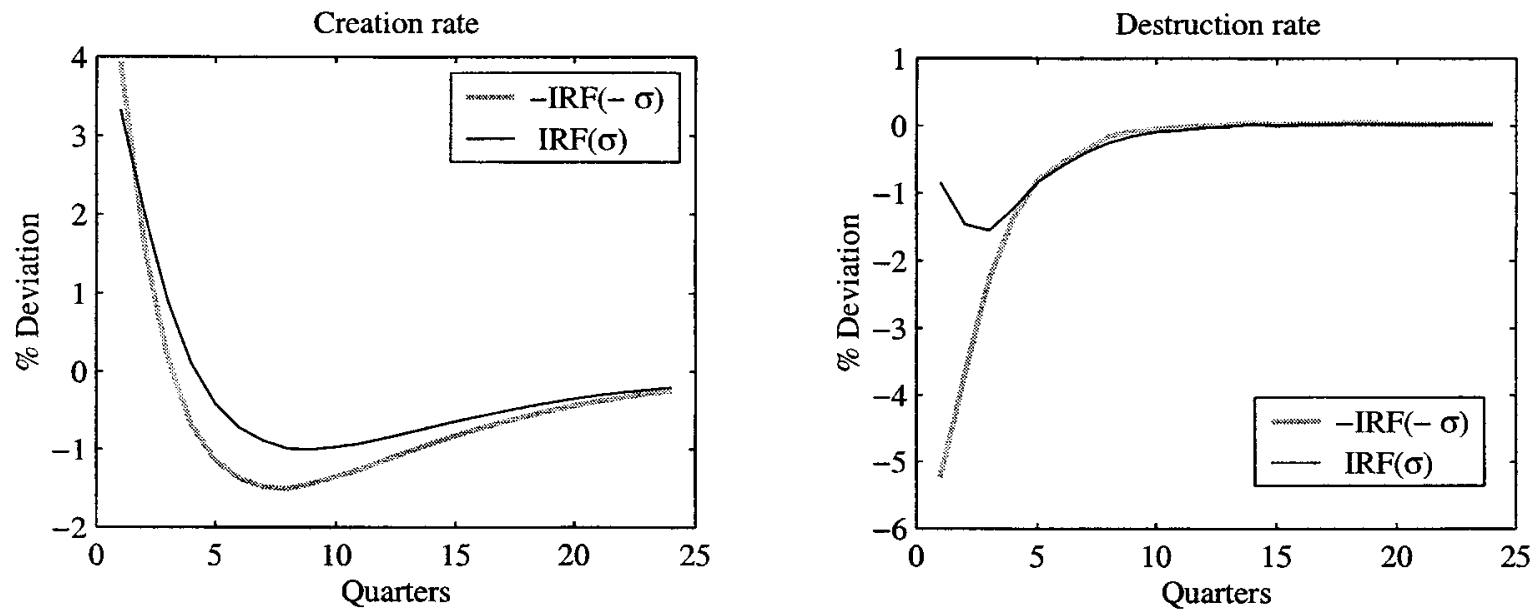

Small Sector
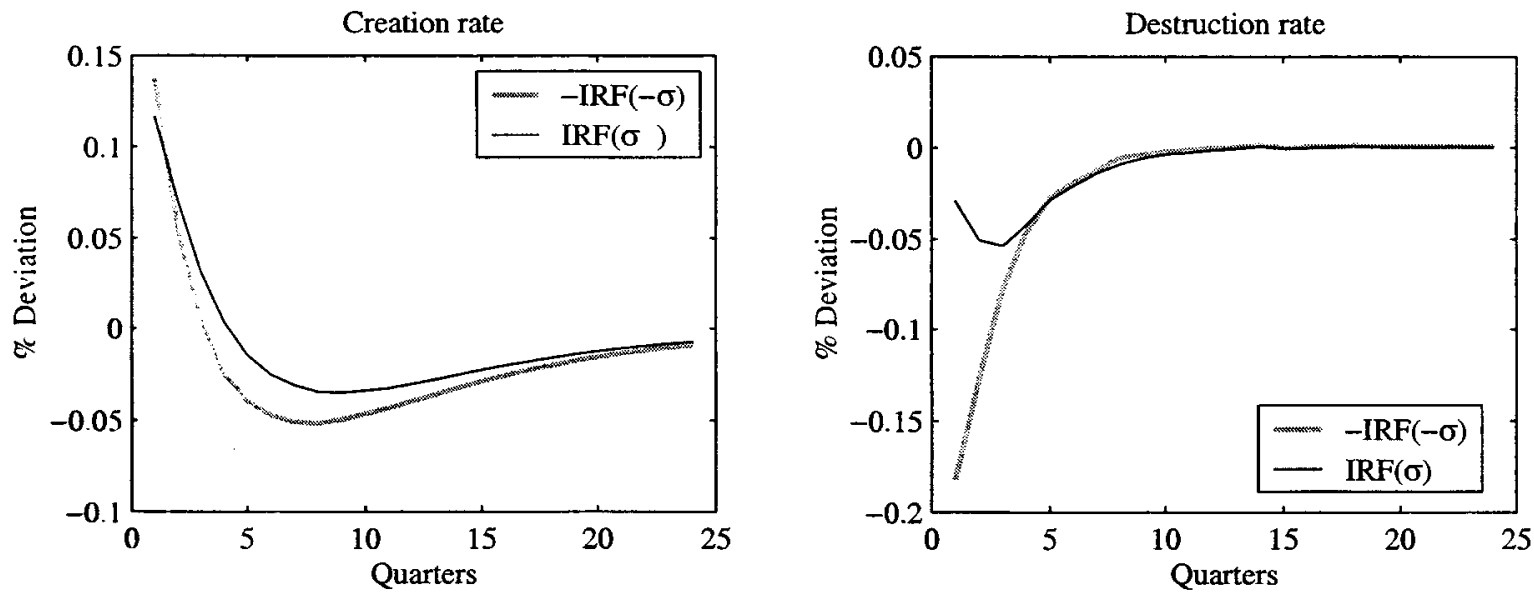

Figure 5: IRF to small versus big sectoral shocks
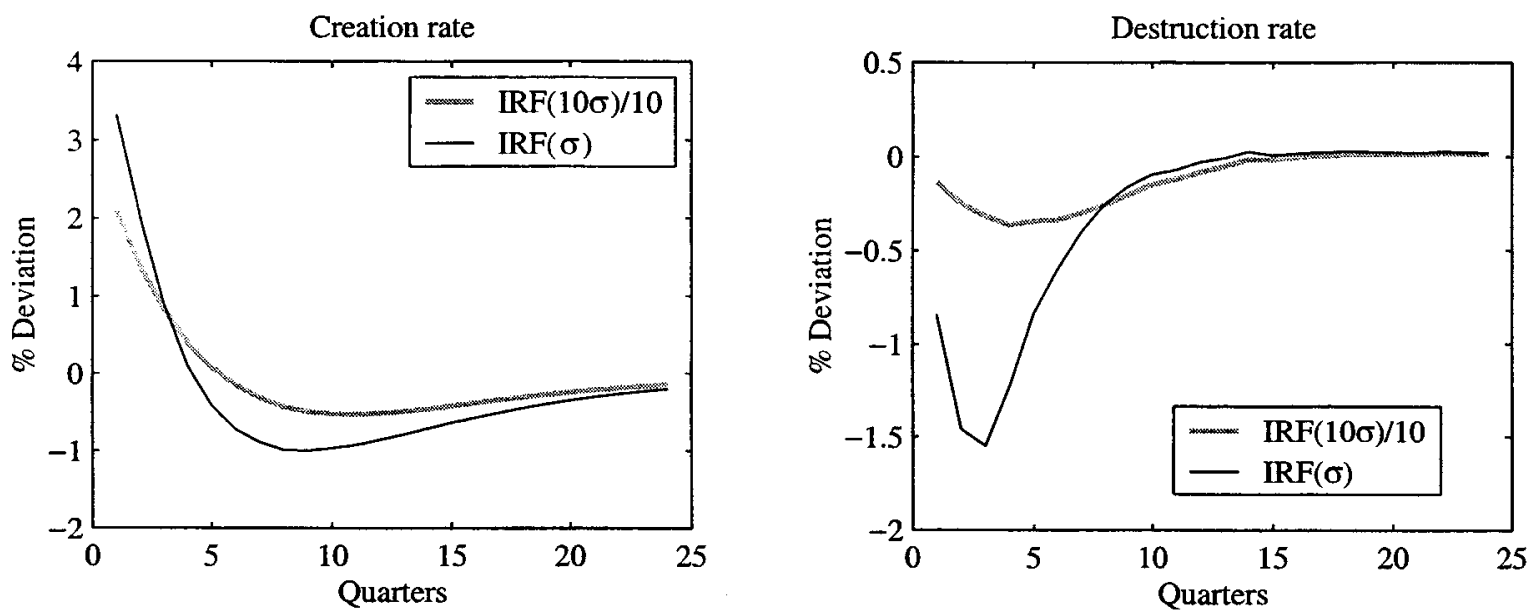
However, the normalized instantaneous response of creations to a big shock is lower than the response to a small shock. Indeed, as the matching function exhibits high decreasing returns to vacancies $(\alpha<0.5)$, the creation rate is a concave function of the marginal value of employment - i.e. sectoral shocks in this model. Then, after several periods, aggregate congestion effects, which are common to all matching models, counter this phenomenon, as it is more difficult to hire in an economy where past hirings were high - implying a lower rate of unemployment. This explains why the normalized IRF to a big shock is above the IRF to a small shock after a while. Concerning destruction rates, firms tend to smooth their firings when larger positive shocks occur. This is easily understood as firing costs are convex.

\section{Concluding remarks}

This paper estimates and tests a structural matching model in the labor market with an explicit modelling of firings. The results show that this representation can account for the distribution of aggregate creation and destruction rates in US data and more particularly their asymmetries. Thus, our findings highlight that the matching mechanism plays an important role in the propagation of sectoral shocks to aggregate employment dynamics. As suggested by Burgess [1992], the non-linear hiring process can explain the asymmetries in aggregate employment dynamics. This model also illustrates the role played by endogenous firing decisions in understanding the non-linear features in employment dynamics. 


\section{Appendix A Proofs of Propositions}

Proposition 1: These results can be directly deduced from the two optimality conditions (4) and (5). Consider the case of a firm that both fires and hires, i.e. $V_{i, j, t}>0$ $\left(\lambda_{i, j, t}=0\right)$ and $F_{i, j, t}>0\left(\mu_{i, j, t}=0\right)$. Then, the optimality condition on vacancies implies

$$
X_{i, j, t}=\frac{\psi^{\prime}\left(V_{i, j, t}\right)}{q_{j, t}}>0
$$

whereas the optimality condition on firings implies

$$
X_{i, j, t}=-\phi^{\prime}\left(F_{i, j, t}\right)<0
$$

These two conditions are mutually inconsistent.

We thus have:

- either $V_{i, j, t}>0$ and $F_{i, j, t}=0$, which implies:

$$
\lambda_{i, j, t}=0 \text { and } \mu_{i, j, t}=\frac{\psi^{\prime}\left(V_{i, j, t}\right)}{q_{j, t}}+\phi^{\prime}(0) \geqslant 0,
$$

- $\quad$ either $V_{j, t}=0$ and $F_{j, t}>0$, which implies:

$$
\lambda_{i, j, t}=\phi^{\prime}\left(F_{i, j, t}\right) q_{j, t}+\psi^{\prime}(0) \geqslant 0 \text { and } \mu_{i, j, t}=0,
$$

- $\quad$ or $V_{i, j, t}=0$ and $F_{i, j, t}=0$, which implies:

$$
\lambda_{i, j, t}=\psi^{\prime}(0)-\left(\mu_{i, j, t}-\phi^{\prime}(0)\right) q_{j, t}
$$

This condition is satisfied as long as $\lambda_{i, j, t} \geqslant 0$ and $\mu_{i, j, t} \geqslant 0-i . e$. as long as $0 \leqslant \mu_{i, j, t}<\psi^{\prime}(0) / q_{j, t}+\phi^{\prime}(0)$

Proposition 2: The envelope condition writes as:

$$
X_{j, t}=\frac{1}{1+r} E_{t}\left[(1+\kappa) \bar{a}+\eta_{j, t+1}-w_{i, j, t}+(1-s) X_{j, t+1}\right] \forall i
$$

given the wage setting behavior, we have, at a symmetric sectoral equilibrium

$$
X_{j, t}=\frac{1}{1+r} E_{t}\left[\bar{a}+\eta_{j, t+1}+(1-s) X_{j, t+1}\right] \forall i
$$


Given the process of the shocks, one can guess a solution of the form:

$$
X_{j, t}=\alpha_{0}+\alpha_{1} \eta_{j, t}
$$

One can then check after some algebra that $\left\{\alpha_{0}, \alpha_{1}\right\}$ are non-linear combinations of the structural parameters of the model. Given the set of the exogenous processes, $\left\{\alpha_{0}, \alpha_{1}\right\}$ are given by the following expression: $\alpha_{0}=\bar{a} /(r+s)$, and $\alpha_{1}=\rho_{\eta}\left(1+r-(1-s) \rho_{\eta}\right)^{-1}$

\section{Appendix B Indirect inference method}

Given a set of moments and the policy functions, the estimation method is conducted as follows:

Step 1: We define in a first step a criterion function, denoted $Q_{T}\left(\underline{c}_{T}, \underline{d}_{T} ; \psi\right)$, where $\underline{c}_{T}=\left(c_{1}, \cdots, c_{T}\right)$ and $\underline{d}_{T}=\left(d_{1}, \cdots, d_{T}\right)$ are observed data on aggregate gross creation and destruction rate respectively and $\psi$ a $q$-dimensional vector of moments, $\psi \in \Psi \subset$ $\mathbb{R}^{q} . \underline{c}_{t}$ (resp. $\underline{d}_{t}$ ) includes contemporaneous and lagged levels and various powers of creation rate (resp. destruction rate) and $\psi$ is the associated moments from the data. We denote $\widehat{\psi}_{T}$ the solution to the minimization of $Q_{T}$ :

$$
\widehat{\psi}_{T}=\operatorname{Arg} \min _{\psi \in \Psi} Q_{T}\left(\underline{c}_{T}, \underline{d}_{T} ; \psi\right)
$$

For $T \rightarrow \infty, Q_{T}$ converges to deterministic limit $Q_{\infty}\left(G_{0} ; \theta_{0} ; \psi\right)$ where $G_{0}$ is the p.d.f. of $\epsilon_{t}$ and $\theta_{0}$ the pseudo-true value of $\theta$. We denote $\psi_{0}=\operatorname{Arg} \max _{\psi} Q_{\infty}\left(G_{0} ; \theta_{0} ; \psi\right)$ and $b(G, \theta)=\operatorname{Arg} \max _{\psi} Q_{\infty}(G ; \theta ; \psi)$, where $b$ is a binding function. When the binding function is known, $\theta$ can be estimated by solving the system $\widehat{\psi}_{T}=b(G, \theta)$. In our case, this function is unknown and we use simulations.

Step 2: From the policy functions, given the structural parameters $\theta$ and an initial condition on employment (denoted $n_{0}$ ), we performs $N$ simulated paths, denoted $\underline{\tilde{c}}_{T}^{i}\left(\theta, n_{0}\right), \tilde{\tilde{d}}_{T}^{i}\left(\theta, n_{0}\right), \quad i=1, \cdots, N$.

Step 3: From these simulations, we get:

$$
\tilde{\psi}_{T}^{i}(\theta)=\operatorname{Arg} \min _{\psi \in \Psi} Q_{T}\left(\tilde{\underline{c}}_{T}^{i}\left(\theta, n_{0}\right), \tilde{\tilde{d}}_{T}^{i}\left(\theta, n_{0}\right) ; \psi\right) \quad i=1, \cdots, N
$$


Step 4: An indirect inference estimator of $\theta$ is defined by choosing a value $\tilde{\theta}_{T}^{N}$ for which $\widehat{\psi}_{t}$ and $\tilde{\psi}_{T}^{N}$ are as close as possible:

$$
\min _{\theta \in \Theta}\left[\widehat{\psi}_{T}-\frac{1}{N} \sum_{i=1}^{N} \tilde{\psi}_{T}^{i}\left(\theta, n_{0}\right)\right]^{\prime} \widehat{W}_{T}\left[\widehat{\psi}_{T}-\frac{1}{N} \sum_{i=1}^{N} \tilde{\psi}_{T}^{i}\left(\theta, n_{0}\right)\right]
$$

where $\widehat{W}_{T}$ is a symmetric nonnegative matrix defining the metric.

Steps 2 to 4 are conducted until convergence, i.e. until a value of $\theta$ which minimizes the objective function is obtained. Under standard regularity conditions, when $N$ is fixed and $T$ goes to infinity, $\sqrt{T}\left(\tilde{\theta}_{T}^{N}-\theta_{0}\right)$ is asymptotically normal, with a covariance matrix equal to $\left(1+\frac{1}{N}\right)\left\{\frac{\partial^{2} Q_{\infty}}{\partial \theta \partial \psi^{\prime}} I_{0}^{-1} \frac{\partial^{2} Q_{\infty}}{\partial \psi \partial \theta^{\prime}}\right\}^{-1}$, where $I_{0}=\lim _{T \rightarrow \infty} V_{0}\left\{\sqrt{T} \frac{\partial Q_{T}\left(\tilde{n}_{T}^{N} ; \psi_{0}\right)}{\partial \psi}\right\}$. The computation of $\tilde{\theta}_{T}^{N}$ necessitates a preliminary consistent estimator of $W_{T}$. The optimal weighting matrix may be directly based on the observations. It corresponds to the inverse of the covariance matrix of $\sqrt{T}\left(\widehat{\psi}_{T}-\psi_{0}\right)$, which is obtained from the first step of the implementation of the estimation method.

\section{Appendix C Computation of Impulse Response Functions}

The computation of the IRF is conducted in the lines of Koop et al. [1996]. In case of an arbitrary shock of magnitude $\delta$, given state variables at time 0 , an IRF for horizon $h$ is defined as:

$$
I_{x}(h, \delta, 0)=E\left[x_{t+h} \mid \delta ; \mathcal{I}_{0}\right]-E_{0}\left[x_{t+h} \mid \mathcal{I}_{0}\right]
$$

where $\mathcal{I}_{0}$ is the information set. Conditional expectations, involved in IRF computations, are calculated using Monte-Carlo integration. Then IRF are obtained as follows:

Step 1: Given an initial value for employment (summarized by $n_{0}$ ), we draw the shocks from $S$ independent normal distributions for a fixed horizon $H$ (summarized by $\nu_{t}$ ). We randomly sample $H \times R$ values for the $S$-dimensional innovation.

Step 2: We compute $R$ realizations for horizon $h=, 0, \ldots, H$ of aggregate creation and destruction rates $-\left\{c_{t}, d_{t}\right\}-$ using the draws from Step 1. They are denoted $c_{h}^{r}\left(n_{0}, \nu_{t}\right)$ and $d_{h}^{r}\left(n_{0}, \nu_{t}\right)$, for $h=0, \ldots, H$ and $r=1, \ldots, R$.

Step 3: We compute $R$ realizations of aggregate creation and destruction rate - 
$\left\{c_{t}, d_{t}\right\}$ - using the same draws plus one additional arbitrary shock $\delta$ in a given sector. They are denoted $c_{h}^{r}\left(n_{0}, \delta, \nu_{t}\right)$ and $d_{h}^{r}\left(n_{0}, \delta, \nu_{t}\right)$, for $h=1, \ldots, H$ and $r=0, \ldots, R$.

Step 4: We form the averages for each simulated data:

$$
\begin{gathered}
\bar{x}_{h, 0}^{R}=\frac{1}{R} \sum_{r=1}^{R} x_{h}^{r}\left(n_{0}, \nu_{t}\right), h=0, \ldots, H \\
\bar{x}_{h, \delta, 0}^{R}=\frac{1}{R} \sum_{r=1}^{R} x_{h}^{r}\left(n_{0}, \delta, \nu_{t}\right), h=0, \ldots, H
\end{gathered}
$$

where $x()=.\{c(),. d()$.$\} .$

Step 5: We compute the IRF as the difference between the two averages of the creation and the destruction rate:

$$
I_{x}(h, \delta, 0)^{R}=\bar{x}_{h, \delta, 0}^{R}-\bar{x}_{h, 0}^{R} \quad h=0, \ldots, H
$$

Thus for $R$ large, we have:

$$
\lim _{R \rightarrow \infty} I_{x}(h, \delta, 0)^{R}=I_{x}(h, \delta, 0) \quad h=0, \ldots, H
$$




\section{References}

Bertola, G. and R.J. Caballero, Cross-Sectional Efficiency and Labour Hoarding in a Matching Model of Unemployment, Review of Economic Studies, 1994, 61, 435456.

Blanchard, O.J. and P. Diamond, The Beveridge Curve, Brookings Papers on Economic Activity, 1989, 1, 1-60.

Burgess, S. M., Nonlinear Dynamics in a Structural model of Employment, Journal of Applied Econometrics, 1992, 7, S101-S118.

Caballero, R.J. and E. Engel, Dynamic of (S,s) Economies, Econometrica, 1991, 59 (6), 1659-1686.

Davis, S.J. and J. Haltiwanger, Gross Job Creation, Gross Job Destruction and Employment Reallocation, Quarterly Journal of Economics, 1992, 107 (3), 819-863.

and S. Schuh, Job Creation and Destruction, Cambridge, Massachusetts: The MIT Press, 1996.

Gallant, R. and G. Tauchen, Which Moments to Match?, Econometric Theory, 1996, $12(4), 657-681$.

D. Hsieh, and G. Tauchen, Estimation of Stochastic Volatility Models with Diagnostics, Working paper, Duke University september 1994.

Gouriéroux, C., A. Monfort, and E. Renault, Indirect Inference, Journal of Applied Econometrics, 1993, 8, S85-S118.

_ and __ Simulation Based Econometric Methods 1994. Core Lecture Series and Cambridge University Press.

Koop, G., M.H. Pesaran, and S.M. Potter, Impulse Response Analysis in Nonlinear Multivariate Models, Journal of Econometrics, 119-147 1996, 74.

Michaelides, A. and S. Ng, Estimating the Rational Expectations Model of Speculative Storage: A Monte-Carlo Comparison of Three Simulation Estimators, Technical Report, Princeton University june 1997.

Mortensen, D.T. and C. Pissarides, Job Creation and Job Destruction in the Theory of Unemployment, Review of Economic Studies, 1994, 61.

Pissarides, C., Unemployment and Vacancies in Britain, Economic Policy, 1986, 3, 498-559.

_ Equilibrium Unemployment Theory, Oxford: Basil Blackwell, 1990.

Smith, A., Estimating Non-Linear Time Series Models Using Simulated Vector Autoregressions, Journal of Applied Econometrics, 1993, 8, S63-S84. 